\title{
Diversity and Temporal Variation of Avian Fauna in a Rice Growing Landscape in Kurunegala District, Sri Lanka
}

\author{
Gunathilake A.M.K.H. and Chandrasekara W.U.* \\ Department of Zoology and Environmental Management, University of Kelaniya, Sri Lanka \\ *upali@kln.ac.lk
}

\begin{abstract}
Rice fields are man-made semi-aquatic ecosystems maintained for the purpose of paddy cultivation. Five contrastingly different successive culture stages viz, preparatory stage, vegetative stage, ripening stage, harvesting stage and post-harvest stage occur along a single paddy culture cycle. Although it has been recorded that a wide variety of fauna are associated with these culture stages, there is a dearth of information on the temporal variation of avian fauna along these culture stages. Therefore, a study was carried out in a rice growing landscape at Katugampola, a rural village in Kurunegala District, to investigate if there is any temporal variation of avian diversity along the culture stages of a paddy culture cycle there. It was hypothesized that the physical and biological characteristics vary along the successive culture stages, and that each culture stage offers a predictable habitat for a distinct assemblage of birds.

The sampling protocol of the study included in situ observation, identification and enumeration of different bird species using the fixed radius point count sampling method, and assessing the physical and biological parameters such as the percentage area covered by paddy plants, height of the paddy plants, number of people, number of off road vehicles, number of cattle, number of dogs, sound level, wind speed and the associated insect fauna at each culture stage using appropriate standard field sampling techniques. The study was commenced in May 2014 and lasted until September 2014.

Altogether 1892 bird counts were made during the study period where the birds belonged into 19 different species and to 12 different families. Physical and biological parameters also varied significantly $(\mathrm{p}<0.05$ Oneway ANOVA) along the paddy culture cycle. Distinct bird assemblages characteristic to each culture stage were recorded during the study. For example, large predatory birds such as Cattle Egret, Intermediate Egret and Little Egret became abundant during the preparatory stage while small seed eating birds such as sparrows became abundant during the ripening and mature stages. Further, large seed eating birds such as Green Imperial Pigeon and Rose-ringed Parakeet became abundant both during the vegetative stage and the post-harvest stage. The temporal variation of the above bird assemblages appeared to have a direct relationship with the variation of the biological and physical parameters along the paddy culture cycle at Katugampola rice field.
\end{abstract}

Keywords: Avian diversity, Rice growing landscapes, Paddy culture cycle

Proceedings of the International Forestry and Environment Symposium 2016, Department of Forestry and Environmental Science, University of Sri Jayewardenepura, Sri Lanka. 